Felisberti, Fatima Maria (2018) Long-lasting effects of family-related factors on adults' ability to recognise brief facial expressions of emotion. Quarterly Journal of Experimental Psychology, 17(7), pp. 1512-1525. Copyright (อ2018 (Experimental Psychology Society). Reprinted by permission of SAGE Publications. https://doi.org/10.1177/1747021817742080. 


\title{
Long-lasting effects of family-related factors on adults' ability to recognise brief facial expressions of emotion
}

\begin{abstract}
This study investigated whether adults' ability to attribute emotions to brief facial expressions (microexpressions) is associated with family-related environmental factors ( $\mathrm{FrFs}$ ) such as one's number of siblings (Experiment 1), attachment style (Experiment 2), or parental authority style (Experiment 3). Participants' accuracy and reaction time (RT) to the recognition of anger, contempt, disgust, fear, happiness, and sadness to facial microexpressions (exposure: $100 \mathrm{~ms}$ ) were measured with a six-alternative forced choice computerised method (6AFC). The attachment style and the authority style of the participants' parents were accessed using questionnaires. The findings revealed that up to $13 \%$ of the variance in participants' responses could be explained by FrFs, with modest to moderate effect sizes. Microexpressions linked to signs of hostility or threat (i.e. contempt and fear) were decoded faster and/or more accurately by adults with few or no siblings or with a fearful attachment. Conversely, participants who recalled their fathers as authoritarian were worse at recognising contempt and fear than participants who perceived them as permissive or authoritative. The findings suggest that early FrFs may still be involved in the fine-tuning of responses to signs of contextual danger when the time for cognitive processing of facial expressions is severely restricted.
\end{abstract}

Keywords: microexpressions, emotion recognition, emotion, parental authority style (PAQ), attachment, siblings. 


\section{Introduction}

The ability to understand and express emotions is essential to successful social interactions and, in some cases, even to survival (Durand, Gallay, Seigneuric, Robichon, \& Jean-Yves, 2007; Elfenbein \& Ambady, 2002; Kestenbaum \& Nelson, 1992; Wills \& Yaeger, 2003). The ability to correctly attribute different emotions to the facial expressions of other humans starts in early childhood and it is strongly affected by parent-child interactions (Camras, Sullivan, \& Michel, 1993; Castro, Halberstadta, Lozada, \& Craig, 2015; Dunsmore, Bradburn, Costanzo, \& Fredrickson, 2009; Halberstadt, 1986). Moreover, such ability is susceptible to a long learning process (Ford \& Mauss, 2015) and the dramatic changes in brain areas involved in emotion processing that occurs during childhood and adolescence can be significantly affected by adverse family-related events (Dahl, 2004) and leave their mark in adulthood.

Facial expressions of emotion are more easily recognised by people who share the same cultural background and/or belong to the same social group (Izard, 1994; S. G. Young \& Hugenberg, 2010). Conversely, the so-called 'basic emotions' (anger, contempt, disgust, fear, happiness, sadness and surprise) are easily recognized independently of the cultural background of the decoder when individuals are given enough time to process them (Dodich et al., 2014; P. Ekman, 1992; P. Ekman et al., 1987; P Ekman \& Oster, 1979). Some aspects of this view have been disputed in recent studies, especially in relation to the effect of culture in the fine-tuning of emotion attribution (Barrett, 2006; Elfenbein \& Ambady, 2002). For example, the eyebrows and mouth seemed to predominate in internal emotional representations in Western Caucasians, while East Asians focused on the eye region and changes in gaze direction (Jack, Caldara, \& Schyns, 2012).

A wide range of experimental paradigms has been used to investigate emotion recognition. Some of them mixed different images of facial expressions of emotion in full intensity to create morphs with varying emotional intensities, which were then used to create video clips (e.g. 100\% fear to $100 \%$ happiness in 100 steps); participants were asked to point in the clips presented when 
they thought a given expression had stopped or started (Biele \& Grabowska, 2006; Halberstadt, Dennis, \& Hess, 2011). Other studies used static emotion morphs (e.g. neutral to $100 \%$ fear in incremental steps) to reveal individual emotion thresholds (Delicato, Finn, Morris, \& Smith, 2014; Roesch, Sander, Mumenthaler, Kerzel, \& Scherer, 2010). Emotion recognition tests with stimuli depicting dynamic changes in facial (and bodily) emotions are also widely used with adults (e.g. the Geneva Emotion Recognition Test (Schlegel, Grandjean, \& Scherer, 2014) and the Bodily Expressive Action Stimulus Test (de Gelder et al., 2006), to cite just a few). In most of those recognition tests emotions are displayed for $2000 \mathrm{~ms}$, a relatively long time for cognitive processing. Certain social contexts or social rules may require individuals to dampen down or hide the emotions expressed in their faces to avoid uncomfortable or confrontational situations. This is a hard task because involuntary facial movements linked to emotions may remain visible for up to $200 \mathrm{~ms}$ before voluntary control can override them (i.e. 'non-verbal emotional leakage') (P. Ekman \& Heider, 1988; Matsumoto et al., 2000). The leaked facial expressions of emotion are referred to as “micro-facial" expressions of emotion or microexpressions, which were initially called "micromomentary expressions" by Haggard and Isaacs (1966).

The introduction of microexpression recognition tests allowed researchers to study emotion recognition when the time for cognitive processing was drastically reduced. The use of microexpressions at their full intensity has some advantages over face morphs since exposures of $\leq$ $200 \mathrm{~ms}$ require fast affective-cognitive processing (i.e. a high level of skill). Moreover, the duration of microexpressions can be easily changed to avoid ceiling accuracy and to limit the time allocated to conscious cognitive processing to seconds or even fractions of seconds.

The wide range of emotion recognition studies has focused on children and adolescents, or on adults who suffered long-term maltreatment in their childhood (c.f. Young \& Widom (2014)). To date, no study has investigated if family-related environmental factors (FrFs) can modulate one's ability to recognise and/or label microexpressions or other short-duration emotion stimuli later in life 
(e.g. adulthood). A strong association between FrFs and an accurate and fast recognition of emotional states to brief facial expressions would suggest that affective processing is a complex combination of innate abilities and vicarious and other forms of social learning, which extends throughout life. Before proceeding, a brief overview of the FrFs addressed in this study is given below.

\section{Number of siblings}

The presence of siblings is frequently linked with a positive contribution to children's social and cognitive development (Morris, Silk, Steinberg, Myers, \& Robinson, 2007; Shortt, Stoolmiller, Smith-Shine, Mark Eddy, \& Sheeber, 2010). According to Downey and Condron (2004) children with siblings showed an improved ability to negotiate peer relationships, but children from smaller families seemed to develop better cognitive skills than children from larger families (Downey, 2001). Furthermore, emotion coaching by mothers - especially of negative emotions such as anger - led to a decrease in externalising that behaviour, whereas displays of anger by older siblings' was linked to an increase in such externalising behaviour in younger siblings (Shortt et al., 2010). However, to date, no study has examined whether the number of siblings can have long-term effects on emotion processing later in life.

\section{Attachment Style}

Since human infancy is prolonged and heavily dependent on parental investment in terms of time, feeding, and protection, there is a need for a coordinated carer-child relationship. Indeed, parents can decode the offspring's signals of fear or distress and provide comfort, protection and a secure base for the exploration of the social environment. Such experiences can be internalised as working models for future relationships and emotion management, as observed in adolescents and adults (Ainsworth, Blehar, Waters, \& Wall, 1978; Bifulco et al., 2006; Cooper, Shaver, \& Collins, 1998; Feeney \& Noller, 1990). In other words, an individual's attachment refers not only to the 
ability of that individual to process her emotions but also to the capacity to respond to the emotions of others. Most studies on attachment refer to four main dimensions (also called "styles" or “orientations”): secure, avoidant (or dismissive), preoccupied, and fearful (Bartholomew \& Horowitz, 1991; Bowlby, 1969). A securely attached adult is comfortable with forming close relationships and is trusting and resilient under stress. Conversely, an adult with an avoidant attachment tends to be a loner, showing discomfort when too close to others and is mistrustful and wary of others' motives. A preoccupied style refers to adults who value intimacy but become overly dependent on their partners and friends for their personal sense of well-being. They are less selfconfident and have high levels of wariness, exaggerated emotionality and impulsiveness, as well as the tendency to idealise other people. Finally, adults with a fearful style wish to have emotionally close relationships, but feel uncomfortable with them. They frequently suppress or deny their feelings because of a fear of rejection, and have low self-esteem and don't trust the intentions of their partners.

The stability of adult attachment styles seems to be similar to the stability observed with personality traits, which showed consistency for periods of up to 25 years (Griffin \& Bartholomew, 1994; Simpson \& Rholes, 1998). However, it is important to remember that the decoding of facial expressions can be modulated by the context in which emotions are displayed. There are many studies about child and adult attachment, but only a few of them show a direct link between attachment style and the ability to decode facial expressions of emotion in unfamiliar faces. One such study reported links between attachment styles and biases for both complex (e.g. shame) and basic (e.g. happiness, disgust) emotions during development (Magai, Hunziker, Mesias, \& Culver, 2000). Another study used video clips of full happiness, anger and sadness turning to neutral expressions and reported that participants with a fearful attachment style perceived the offset of happiness and anger expressions earlier than the securely attached ones; avoidant and preoccupied participants perceived the offset later (Niedenthal, Brauer, Robin, \& Innes-Ker, 2002). However, to 
date, no study has examined possible links between the recognition of a large set of microexpressions and adult attachment.

\section{Parental Authority Style (PAS)}

There are many dimensions to parenting in Western societies (i.e. warmth, acceptance, responsiveness, control, and autonomy granting), which are linked to the development of social competence (Shaffer, Burt, Obradovic, Herbers, \& Masten, 2009). According to Buri (Buri, 1991; Buri, Louiselle, Misukanis, \& Mueller, 1988), parental styles can be grouped in core dimensions linked to the early child-carer relationship, which is reflected in studies about parental authority: authoritative, authoritarian, and permissive styles. Authoritative parenting is exemplified by a moderate level of demands and moderate-to-high responsiveness to children's needs. Authoritative parents give direction to their children, but these are tempered with warmth and flexibility, which helps children to be consistently more socially competent than children whose parents displayed different parenting styles. Authoritarian parents tend to be highly directive of their children's activities demanding their unquestioning obedience. This style is characterised by a high level of demands, limited parenting warmth, and a low degree of responsiveness to the offspring's needs. Permissive parenting had a low level of demands and children were left alone to explore their environment, receiving little or no parental guidance; the children were less self-assertive when compared with those from homes with authoritative parents.

The emotional competence of parents was shown to be relevant and directly linked to the emotional competence of their children (Telzer et al., 2014). Men and women tend to recall fathers as more authoritarian and mothers as more authoritative (Collins \& Russell, 1991; Klein, O'bryant, \& Hopkins, 1996). A paternal authoritative style was frequently associated with positive selfperceptions suggesting that participants perceived such fathers as offering protection and autonomy (Baumrind, 1971, 1991). Conversely, perceived authoritarian paternal style was linked to negative 
self-perceptions (Cui, Morris, Criss, Houltberg, \& Silk, 2014). Studies about the effects of parental authority on affective processing have tended to focus on adults who suffered abuse and/or neglect during their childhood (Young \& Widom, 2014). To date, nothing is known about effects of perceived parental style on the recognition of emotions to facial expressions in typical adults.

In a nutshell, typical and healthy adults can recognise basic facial expressions of emotion when presented in full intensity and enough time is allowed for cognitive appraisal. This ability is modelled by a wide range of factors and is susceptible to continuous learning as individuals move from childhood into adulthood. Nonetheless, it is surprising how little is known about the role of early FrFs on affective processing in later life. This is the first study to investigate the contribution of early FrFs to adults' ability to attribute plausible emotional states to briefly presented facial expressions. Three FrFs were chosen because they are strongly linked to different aspects of early social interactions that may have lasting effects on adults' ability to recognise the so-called "basic emotions" when the time allocated for cognitive processing was restricted: number of siblings (factual data), attachment style (self-reported representations of the self in relation to close relationships), and parental authority style (recollection of parental authority). 


\section{Experiment 1: Microexpressions and the number of siblings}

This experiment addressed two separate questions. The first part of the experiment reports the participants' accuracy and reaction time (RT) to six microexpressions (anger, contempt, disgust, fear, happiness, sadness) and tries to replicate the general response trends observed in previous studies using a similar experimental paradigm. The second part of the experiment investigates if the number of siblings could be a reliable predictor of the variability in the adults' accuracy and RT for the microexpressions tested.

\section{Method \\ Participants}

The initial dataset had 137 participants (110 females, 27 males; $M$ age $=22.2, S D=6.2$ years). Four percent of the participants were excluded from the original dataset for assorted reasons: disruptive noises (e.g. persistent ringtones from mobile phones, fire drills), performance at chance level for two or more of the emotions presented, mean accuracy values outside three standard deviations of the mean, and unfinished questionnaires. These problems were usually reflected in the participant's response latency; if RT was $<100 \mathrm{~ms}$ (too fast for accurate processing) or $>10000 \mathrm{~ms}$ (unusually long post-stimulus time lag) for more than two microexpressions, the participant was excluded from the data analysis. The missing values were replaced by the sample mean for each specific microexpression.

The sample size in this and the following experiments was larger than 48 participants to achieve $80 \%$ power to detect significant microexpressions interactions $(p=.01)$ of effect size $f=.20$ $\left(f=\operatorname{sqrt}\left(\eta^{2} /\left(1-\eta^{2}\right)\right)\right.$, with a .40 correlation estimated among repeated measures (Faul, Erdfelder, Lang, \& Buchner, 2007). Larger sample sizes were used in this and the following experiments to account for eventual outliers and missing data. Participants were mostly university students and a few graduate adults, who were recruited via opportunity sampling (e.g. ads in the University 
recruitment system, leaflets, or word of mouth). All participants had normal or corrected-to-normal vision. The Ethics Committee at the School of Social and Behavioural Sciences approved the research protocols, and the experiments were conducted according to the ethical standards of the Declaration of Helsinki 1964. All participants in this and the following experiments provided informed consent. No cash payments were made, but students could opt to receive course credits for their participation.

\section{Materials}

The stimuli consisted of six microexpressions of emotion (anger, contempt, disgust, fear, happiness, and sadness) from 24 different Caucasian actors (12 females and 12 males) and their correspondent neutral faces. The facial expressions and correspondent neutral faces were obtained from the Japanese and Caucasian Facial Expressions of Emotion (JACFEE/JACneu) (Matsumoto \& Ekman, 1988). The test was similar to JACBART (Japanese and Caucasian Brief Affect Recognition Test) (Matsumoto et al., 2000), but the actors' hair, visible clothing, and external facial contour were digitally erased with Photoshop CS5. The final image had the internal facial expressions from the Caucasian actors overlaid on Caucasian avatars created with FaceGen Modeller 3.5 software. The new stimuli allowed participants to focus their attention on the very brief facial expressions of emotion (Figure 1).

The microexpression recognition test was generated with E-Prime ${ }^{\circledR} 2.0$ software (Psychology Software Tools Inc., Pittsburgh, PA) and it was based on the microexpressions training tool developed by Ekman and others (P Ekman \& Friesen, 1978; Matsumoto et al., 2000). The images were presented at the centre of the screen and subtended approximately $8 \times 7$ degrees of visual angle at approximately $60 \mathrm{~cm}$ from the screen. The duration of the microexpressions was $100 \mathrm{~ms}$, and the response was given by mouse clicking on the appropriate emotional label on the test screen. There were 48 trials per participant: 6 microexpressions x 4 actors ( 2 males, 2 females) x 2 repetitions. 


\section{Procedure}

The computerised microexpressions test started with the presentation of six black and white pictures of facial expressions of emotion (images from Ekman's studies freely available on the Internet). The emotions were labelled to familiarise participants with the discrete emotion concepts used in the answer boxes in the experiment. That short practice phase was necessary, as familiarity with concepts can modulate emotion perceptions regarding the response speed and sensitivity (Nook, Lindquist, \& Zaki, 2015). Those images were different from the faces presented in the subsequent phases of the test.

The following test practice had a sequence of three images: a $1000 \mathrm{~ms}$ neutral expression, a $300 \mathrm{~ms}$ emotional expression, and the same $1000 \mathrm{~ms}$ neutral expression. Six microexpressions were presented; the neutral faces presented before the microexpressions allowed participants to evaluate the neutral expression of each actor and act as a 'stimulus reset' stage. The neutral face presented after the microexpressions acted as a post-stimulus mask, disrupting the memorization of microexpressions prior to response input. This 'practice test' was introduced because speed and accuracy were essential variables in this study. The microexpressions recognition test was identical to the practice test, except for the duration of the microexpressions, which was shorter (100 ms). Participants were asked to answer as fast and as accurately as possible. Feedback was provided after each trial (i.e. percentage of correct responses). It is worth noting that a pilot test $(N=39)$ was run prior to data collection to check if the right/left location of the emotion labels could lead to hemispheric bias regarding accuracy and RT. The findings showed no consistent biases linked to their right or left positions.

\section{Data analysis}


The findings in this and all the following experiments in this study were assessed for normality; mean accuracy and RT were accepted as having a normal distribution if the kurtosis fell in the range of \pm 2.0. Kurtotic mean distributions outside that range were normalised using Box-Cox transformations (usually accuracy ${ }^{2}$ and $1 / \sqrt{ } \mathrm{RT}$ ) (Box \& Cox, 1964). The distribution of happiness accuracy responses was heavily skewed towards ceiling accuracy (i.e. 100\%), and therefore it was excluded from the statistical analysis. The inclusion of a joyful and easily recognisable microexpression was necessary to control the level of participants' attention during the trials (i.e. low accuracy could indicate a high level of distraction) and to provide a counterbalance to the expressions with a negative valence. Missing values due to response delays $>10 \mathrm{~s}$ were replaced by the sample average for the corresponding microexpression.

The repeated-measures analysis of variance (ANOVA) was used in the first part of the experiment (i.e. microexpressions test), and Greenhouse-Geisser adjustments to the degrees of freedom were performed when sphericity could not be assumed (Mauchly's sphericity test). Pairwise comparisons were performed with Bonferroni adjustments, and eta-square $\left(\eta^{2}\right)$ was used here to refer to effect size, as it has been indicated as more suitable for comparisons across the different experiments (Levine \& Hullett, 2002 ). Effect size values had the following approximate cut-off values: 0.01 small/modest, 0.06 medium/moderate, and 0.14 large. However, such cut-off values should be taken as "rules of thumb" rather than precise boundaries (Cohen, 1990, 1992). The Bayesian repeated-measures ANOVA, carried out using JASP software ( $r$ scale fixed effects of 0.5 and covariates of 0.354 ), was used to evaluate the evidence for or against the alternative and the null hypotheses (Marsman \& Wagenmakers, 2016; Wagenmakers, 2016). $\mathrm{BF}_{10}$ values below 0.1 suggest some evidence in favour of the null hypothesis and values above 1 indicate some evidence in favour of the alternative hypothesis $\left(\mathrm{BF}_{10}=1-3\right.$ weak, $3-10$ moderate, $\geq 10$ strong evidence). Linear regression and Bayesian regression analysis were employed to examine how much of the variance in the RT and accuracy to microexpressions was predicted by the participants' number of siblings. 


\section{Results}

Microexpressions test

Accuracy. A 5 (microexpressions: anger, contempt, disgust, fear, sadness) x 2 (gender) ANOVA showed that accuracy varied with the microexpressions $\left(F(4,540)=27.08, p<.001, \eta^{2}=\right.$ $.167)$ and the effect size was large. There was no significant effect of the participants' gender on accuracy $\left(F(4,540)=.885, p=.473, \eta^{2}=.007\right)$. Usually, participants were more accurate decoding contempt and less accurate decoding disgust $(p<.01)$ than the other microexpressions (Table 1$)$.

The Bayesian analysis of accuracy confirmed that there was strong evidence in favour of the alternative hypothesis $(\mathrm{BF} 10=7.547 \mathrm{e} .+32)$. In other words, the accuracy in the recognition of affective states varied strongly with the microexpression presented. Again, there was no evidence supporting (or clearly rejecting) gender differences in emotion recognition $(\mathrm{BF} 10=0.212$ ).

$R T$. A Box-Cox transformation $(1 / \sqrt{ } \mathrm{RT})$ was used to bring kurtosis into the \pm 2 range. As observed with accuracy, RT varied with the microexpressions presented $(F(3.73,504.53)=11.01, p$ $\left.<.001, \eta^{2}=.075\right)$ and the effect size was moderate. The RT for contempt was faster than for the other emotions $(p<.003)$ (Table 1$)$. No significant interaction between gender and the RT was observed $\left(F(3.73,504.53)=.923, p=.450, \eta^{2}=.007\right)$. A Bayesian ANOVA also revealed strong evidence that RT varied with different microexpressions $(B F 10=3.627 \mathrm{e} .+7)$, but there was no evidence supporting the influence of gender differences in those RT responses $(\mathrm{BF} 10=0.402)$.

\section{-----TABLE 1 AROUND HERE------}

\section{Number of siblings and Microexpressions}

The number of siblings per participant in this experiment was as follow: no siblings $(N=16)$, one $(N=51)$, two $(N=39)$, three $(N=15)$, and $\geq 4$ siblings $(N=15)$.

Accuracy. A correlation analysis showed that as the number of siblings increased, the accuracy for fear decreased $(r=-.18, p=.034)$ (Table 2). A linear regression showed that the number of siblings contributed up to $3 \%$ of the variance observed in the accuracy for fear $(F(1,136)$ 
$=4.581, p=.034$ ) (Table 3). The influence of the number of siblings on adults' ability to recognize briefly flashed fearful expressions was supported by the Bayesian regression analysis, but only weakly $(\mathrm{BF} 10=1.453)$.

$\boldsymbol{R T}$. A negative correlation was observed between the number of siblings and the RT for sadness $(r=-.255, p=.003)$ and contempt $(r=-.181, p=.034)$; the number of siblings contributed to $6 \%$ of the variance in response latency for sadness $(F(1,136)=9.381, p=.003)$ and up to $3 \%$ for contempt $(F(1,136)=4.567, p=.034)$ (Table 3). A Bayesian regression analysis showed strong evidence in favour of an effect of the number of siblings in the recognition of sadness $(\mathrm{BF} 10=$ 12.120), but evidence for its effect on the recognition of contempt was weak $(\mathrm{BF} 10=1.444)$.

\section{Discussion}

The duration of the microexpressions used in previous studies varied between 40-200 ms (c.f. Ekman \& Oster (1979), Kemeny et al. (2012), Shen, Wu, \& Fu (2012)); therefore, direct comparisons between the different sets of findings can only be made regarding response trends. Nonetheless, the findings reported here were in line with the findings in those studies regarding the overall accuracy to the different microexpressions. The accuracy for all microexpressions was above chance and below the $100 \%$ accuracy ceiling (except for happiness). Contrary to initial predictions, the recognition of fear decreased as the number of siblings increased and the same was true for anger, but to a lesser degree. In other words, having siblings to interact with didn't lead to a more accurate emotion recognition to the microexpressions (i.e. via vicarious learning, (Eisenberg et al., 1991; Fabes et al., 1994). Instead, it was the absence of siblings (or a reduced number of them) that had a stronger modulatory effect on adults' ability to recognise quick facial displays of fear. On the other hand, the recognition of sadness improved when the number of siblings was larger (i.e. low RT) and a similar trend was observed with the recognition of contempt. Those findings suggest a 
divergent and non-linear relationship between the number of siblings and the ability to recognise microexpressions.

1

2

5

6

7

8

9

10

11

12

13

14

15

16

17

18

19

20

21

22

23

24

25

26

27

28

29

30

31

32

33

34

35

36

37

38

39

40

41

42

43

44

45

46

47

48

49

50

51

52

53

54

55

56

57

58

59

60 


\section{Experiment 2: Microexpressions and attachment style}

This experiment investigated whether the participant's attachment style (secure, fearful, preoccupied, or avoidant) was associated with a differentiated ability to interpret microexpressions.

\section{Method}

Participants

There were 79 participants ( 58 females, 21 males; $M$ age $=23$ years, $S D=4$ years ) and the duration of microexpressions was $100 \mathrm{~ms}$.

\section{Materials}

The microexpressions test was the same used in Experiment 1. The Relationships Questionnaire (Bartholomew \& Horowitz, 1991) is a 4-item questionnaire designed to measure adult attachment style and uses a seven-point Likert scale ranging from 1 ("not at all like me") to 7 ("very much like me"). The questions were a rewording of attachment style descriptions from the ThreeCategory Measure (Hazan \& Shaver, 1987) adding the avoidant-dismissive style. The RQ contains the following statements: secure ("It is easy for me to become emotionally close to others"), preoccupied ("I am uncomfortable getting close to others"), fearful ("I want to be completely emotionally intimate with others, but I often find that others are reluctant to get as close as I would like"), and avoidant ("I am comfortable without close emotional relationships"). Participants rated the items on the Likert scale and their scores for each of the four attachment styles was used in the data analysis.

\section{Results}

According to their RQ scores, participants were allocated to the following attachment styles: secure (50.6\%), fearful (17.7\%), preoccupied (11.4\%), and avoidant (20.3\%). Participants were recruited until the distribution of attachment styles was similar to the one observed by Bartholomew and Horowitz (1991), but the sample tended naturally to towards that distribution. Participants with 
equal scores for two or more styles (which included secure) were allocated to the secure style $(N=$ 3). Raw scores, rather than categories were used in the data analysis. A Pearson correlation matrix revealed that the secure style was negatively correlated with the fearful $(r=-.365, p=.001)$ and avoidant $(r=-.248, p=.027)$ styles, whereas the preoccupied style was positively correlated with the fearful style $(r=.336, p=.002)$; no other significant correlations were observed (Table 4).

Accuracy. It varied significantly with the microexpression presented $(F(3.20,246.70)=34.33$, $\left.p<.001, \eta^{2}=.308\right)$ and there was no interaction between gender and accuracy $(F(3.21,247.18)=$ $\left.0.085, p=.987, \eta^{2}=.001\right)$. The recognition of contempt $(92 \%)$ was better than for other microexpressions, except for happiness and fear $(p>.50)$, whereas disgust and anger were the hardest emotions to recognise (68\% and 65\%, respectively) (Table 1). No reliable correlations were observed between microexpressions accuracy and the four attachment styles.

$\boldsymbol{R} \boldsymbol{T}$. The time taken to recognize each microexpression was similar $(F(3.75,288.07)=1.896, p$ $\left.<.11, \eta^{2}=.024\right)$ and there was no interaction between gender and $\operatorname{RT}(F(3.75,288.07)=0.195, p=$ $\left..941, \eta^{2}=.003\right)$. The fearful attachment was negatively correlated with the recognition of fear $(r=-$ $.26, p=.023)$, i.e., the higher the score for a fearful attachment, the slower the RT to fear. However, the association was relatively weak, explaining only up to $5 \%$ of the response variance $(F(1,78)=$ 5.247, $p=.025$ ) (Table 3). A subsequent Bayesian regression analysis supported a moderate effect of fearful attachment on the recognition of fear $(\mathrm{BF}=2.291)$.

\section{Discussion}

The accuracy to all microexpressions in this experiment was slightly (and monotonically) higher than the accuracy reported in Experiment 1, except for happiness which was at or near ceiling in all experiments. Since the response latency to correct responses (i.e. RT) was slower, the findings point to a small accuracy-RT trade-off: higher accuracy required a time to respond and vice-versa.

Previous studies reported that one's attachment style could modulate affective processing (c.f. Niedenthal et al. (2002)) and that attachment anxiety could lead to a heightened state of vigilance to 
1

2

3

4

5

6

7

8

9

10

11

12

13

14

15

16

17

18

19

20

21

22

23

24

25

26

27

28

29

30

31

32

33

34

35

36

37

38

39

40

41

42

43

44

45

46

47

48

49

50

51

52

53

54

55

56

57

58

59

60

facial cues imbued with social and emotional meanings (Fraley, Niedenthal, Marks, Brumbaugh, \& Vicary, 2006). Although the preoccupied and fearful styles were positively correlated, the questions related to those styles are diametrically opposed ("I am uncomfortable getting close to others" vs. "I want to be completely emotionally intimate with others, but I often find that others are reluctant to get as close as I would like", respectively). Both constructs characterised a negative model of the self, since they rely heavily on the acceptance and affirmation of others, but whilst preoccupied attachment relates to a positive model of others (i.e. approach), fearful attachment relates more closely to a negative model of otheres (i.e. avoidance) (Bartholomew \& Shaver, 1998).

The findings from this experiment revealed that adults with a more fearful attachment were slower at recognising fear in brief facial expressions. Based on previous studies using the RQ, the number participants recruited on each category was representative of the population, but it is possible that a larger sample or a more detailed attachment questionnaire would reveal more significant associations (Ravitz, Maunder, Hunter, Stankiya, \& Lancee, 2010). 


\title{
Experiment 3: Perceived Parental Authority Style (PAS)
}

The main aim of this experiment was to examine whether the individual biases observed in the recognition of microexpressions could be predicted by the scores of perceived PAS (permissive, authoritarian, and authoritative) of the participants' mothers and fathers. PAS is also referred to as PAQ (Parental Authority Questionnaire).

\author{
Method \\ Participants \\ There were 65 participants ( 43 females, 22 males; $M$ age $=33$ years, $S D=14$ years). \\ Participants were slightly older than in the previous experiments, and none of them was living with \\ their parents. All participants had normal or corrected-to-normal vision. See Experiment 1 for details \\ about participants' recruitment and ethics consent.
}

\section{Materials}

The microexpressions test used in this experiment was the same employed in the previous two experiments. The PAS questionnaire (Buri, 1991) has two forms, one to describe fathers and a parallel one to describe mothers. Each form contains 30 items, all based on Baumrind's (1971) definitions of parental styles: 10 authoritative, 10 authoritarian, and 10 permissive. An example of an authoritative item is "As I was growing up my mother/father directed the activities and decisions of the children in the family through reasoning and discipline"; a permissive item is "As I was growing up my mother/father did not feel that I needed to obey rules and regulations of behaviour simply because someone in authority had established them"; and an authoritarian item is "As I was growing up my mother/father did not allow me to question any decision she had made. Participants had to respond using a 5-point scale ranging from strongly disagree (1) to strongly agree (5). The validity of the content, criterion, and discriminant was high (Buri et al., 1988) and test-retest reliability ranged from .77 to .92 (Buri, 1989). 
Data analysis

Heavily kurtotic mean distributions for the responses in the microexpressions test were normalised using Box-Cox transformations (accuracy ${ }^{2}$ and 1/ $\sqrt{R T}$ ) (Box \& Cox, 1964). No clear multicollinearity was observed between mothers' and fathers' authority styles (VIF coefficients < 1.5). Box-Cox transformations $\left(\mathrm{ACC}^{2}\right.$ and $1 / \sqrt{ } \mathrm{RT}$ ) were used to bring kurtosis into the \pm 2 range. Results

Taking the highest scores for the subscales in the PAS questionnaire, participants recalled their mothers as authoritative $(N=36)$, authoritarian $(N=22)$, or permissive $(N=7)$ and their fathers as authoritative $(N=21)$, authoritarian $(N=24)$, or permissive $(N=20)$. Averaged Cronbach alphas for mothers and fathers were 0.90 (authoritative), 0.89 (authoritarian), and 0.78 (permissive).

Table 4 shows a correlation matrix for PAS: fathers parental styles were negatively correlated $(r=-.284$ to $-.437, p<.05)$, except for a positive correlation between permissive fathers and authoritative fathers $(r=.254, p=.04)$. Maternal authority styles were negatively correlated $(r=$ .552 to $-.574, p<.001$ ), except for the permissive and authoritative (no significant correlation). The only significant correlation between maternal and paternal authority styles was a negative correlation between permissive fathers and authoritative mothers $(r=-.303, p=.01)$.

Accuracy. As reported in the previous experiments, the ANOVA showed that accuracy varied significantly with the microexpression presented $\left(F(4,252)=32.94, p<.001, \eta^{2}=.335\right)$, but no gender interaction with accuracy was observed $\left(F(4,252)=2.36, p=.054, \eta^{2}=.024\right)$. Regression analysis was used to examine if the maternal and paternal PAS scores in each of the three sub-scales could predict the variability in the accuracy and RT responses for microexpressions.

Maternal authority style. A regression analysis showed a significant correlation between the authoritative maternal style and the accuracy for sadness $(r=.316, p=.010)$. The authoritative maternal style explained $8.6 \%$ of the variance in the response to sadness $(F(1,64)=6.997, p=.010)$ (Table 3). The permissive and authoritarian styles had no significant effect on the recognition 
accuracy. A Bayesian regression confirmed there was (moderate) evidence of modulation of sadness recognition by an authoritative maternal style $(\mathrm{BF}=4.543)$.

Paternal authority style. There were significant correlations between contempt's accuracy and the permissive $(r=.316, p=.010)$, authoritarian $(r=-.319, p=.010)$, and authoritative $(r=.281, p$ $=.037$ ) perceived parental styles. A regression analysis (entry order: authoritarian, permissive, and authoritative) showed that paternal authority styles accounted for up to $12 \%$ ( $R$ squared) of the accuracy variability for contempt, with the authoritarian style contributing $9 \%(F(3,64)=7.12, p=$ $.010)$ and the permissive and authoritative styles contributing a further $3 \%(F(3,64)=5.06, p=.009$ and $F(3,64)=3.94, p=.012$, respectively). In addition, an authoritarian style was negatively correlated with the accuracy for fear $(r=-.378, p=.002)$, which explained about $13 \%$ of the variance observed in the response $(F(1,64)=10.53, p=.002)$. The findings were also analysed with a Bayesian regression, which revealed that the evidence for the modulation of contempt accuracy was moderate in participants who perceived the authority style of their fathers as being permissive $(\mathrm{BF}=4.561)$ or authoritarian $(\mathrm{BF}=4.773)$ or weak evidence in the case of authoritative fathers $(\mathrm{BF}$ $=1.701)$.

$\boldsymbol{R T}$. It varied with the microexpressions $\left(F(4,252)=5.80, p<.001, \eta^{2}=.083\right)$ and no significant effect of gender on accuracy was observed $\left(F(4,252)=1.20, p=.310, \eta^{2}=.017\right)$. Maternal authority style. No significant correlation was observed between the RT to microexpressions and the perceived maternal authority style.

Paternal authority style. Participants with perceived their fathers as permissive were slower to decode microexpressions of anger $(r=.31, p=.011)$ and contempt $(r=.31, p=.012)$. Having permissive fathers helped to explain about $8 \%$ of the variance in the RT to anger and contempt ( $F(1$, $64)=4.98, p=.0 .29)$ (Table 3). Finally, a Bayesian regression confirmed that there was evidence of modulation of $\mathrm{RT}$ for contempt $(\mathrm{BF}=4.085)$ or anger $(\mathrm{BF}=4.223)$ by permissive fathers. 


\title{
Discussion
}

\begin{abstract}
A comparison of all accuracy data across all microexpressions revealed that were uniformily higher in participants who completed the RS (Expt.2) and PAS (Expt. 3) questions than in participants simply asked to provide information about their siblings (Expt. 1), which suggests a heightened engagement with the test when participants were asked to reflect on different aspects of their lives.

Adults who perceived their parents as being authoritative would be expected to respond to microexpressions in a more contextually adjusted way than adults who perceived their parents as being authoritarian. Surprisingly, the perceived authority style of mothers did not seem to affect the accuracy or RT to microexpressions markedly, except for an increase in accuracy to sadness in the participants who perceived their mothers as authoritative. Having fathers perceived as authoritarian predicted a lower accuracy for contempt and fear, whereas perceived permissive fathers were associated with a longer RT to anger and contempt in comparison to adults with fathers recalled as authoritative.
\end{abstract}




\section{General Discussion}

Studies on health and developmental psychology attest that adults benefit from a favourable early family environment (c.f. Halberstadt et al. (2011), Kiel \& Kalomiris (2015)), where among other skills they develop and hone abilities essential to daily social interactions and exchanges. This study examined if adults' ability to attribute precise emotions to micro-facial expressions was still modulated by early FrFs such as the number of siblings, attachment style, and perceived parental authority style.

Experiment 1 showed that the mean accuracy and RT for the recognition of microexpressions varied with the emotion displayed (Biehl et al., 1997; Matsumoto \& Ekman, 1988; Palermo \& Coltheart, 2004; Shen et al., 2012): happiness and contempt were recognized accurately and fast, whereas anger and disgust were comparatively harder to recognize. Although there was variation in the individual responses to each microexpression, the $100 \mathrm{~ms}$ duration was within the optimal range for the onset phase of microexpressions (65-260 ms) (Yan, Wu, Liang, Chen, \& Fu, 2013). The overall recognition of affective states to the microexpressions was relatively good (i.e. above chance level) and below ceiling response, an ideal response range to investigate eventual associations between FrFs and microexpression recognition.

The findings in Experiment 1 showed that adults' accuracy for fear decreases with the number of siblings. The findings did not fully support the hypothesis that vicarious learning among siblings. Although siblings play a major role in socialisation and vicarious emotional learning and help each other to improve their chances of survival until sexual maturity, despite the competition for parental resources (Morris et al., 2007; Nitsch, Faurie, \& Lummaa, 2013), an increase in the number of siblings was not linked to a better recognition of fear later in life. It is possible that adults with one or no siblings to protect them when they were young might have had to learn to decode brief facial expressions signalling danger more accurately than the ones who felt protected by their siblings. Conversely, it is equally possible that adults with many siblings had learned to pay less attention to 
fearful facial microexpressions to minimise infighting or arguments, but further studies with typical adults are needed to verify such hypotheses.

In agreement with previous studies, the gender of the participants did not affect the recognition accuracy for microexpressions significantly (Hess, Blairy, \& Kleck, 1997; Palermo \& Coltheart, 2004), although such results are in conflict with the gender differences reported by Safer (1981).

The findings in Experiment 2 showed that a fearful attachment predicted a faster RT to fear, which is in line with studies suggesting that one's attachment style can modulate affective processing (Niedenthal, et al., 2002) and that attachment anxiety could lead to a heightened state of vigilance to facial cues imbued with emotional meanings (Fraley, Niedenthal, Marks, Brumbaugh, \& Vicary, 2006). It is also well established that attachment is strongly affected by the quality of early carerchild interactions (Castro, et al., 2015; McElwain, Halberstadt, \& Volling, 2007; Salcuni, 2015), which can extend into adolescence (Canetti, et al., 1997; Cooper, et al., 1998).

Experiment 3 examined the role of parenting authority styles in the response to microexpressions in adults. An authoritative parenting style was shown to be a predictor of good adaptive emotion regulation in children aged 12-15, whereas an authoritarian parenting predicted less adaptive emotion regulation (Karim, Sharafat, \& Mahmud, 2013). Moreover, the high parental control common in authoritarian parents is associated with poor emotional regulation and internalized (i.e. anxiety, depression) as well as externalized (i.e. delinquency, aggression) problems in adolescents (Barber, 1996; Bean, Bush, McKenry, \& Wilson, 2003; Cui et al., 2014; Kunz \& Grych, 2013; Silk, Steinberg, \& Morris, 2003).

The findings revealed a positive and significant correlation between the accuracy for contempt and the scores for the permissive paternal authority, but a negative correlation with the scores for an authoritarian style. More frequently than not, parents help to improve emotional regulation and understanding in their offspring (McElwain, Halberstadt, \& Volling, 2007). Hence, it could be reasoned that authoritarian fathers would discourage facial expressions of contempt and fear in their 
offspring, which might have led to a reduced sensitivity (i.e. increased perceptual thresholds) to those microexpressions. Conversely, a lower accuracy for contempt and fear could be a by-product of "learned helplessness" (Hiroto, 1974; Hiroto \& Seligman, 1975): adults who endured—or were over exposed to-aversive emotions in their childhood and adolescence (even if mild or moderate) would have learned to avoid to attend appropriately to those emotions, which would impair or dampen their ability to decode those microexpressions later in life. Indeed, a reduction in brain activity in the circuitry underpining the social processing of fear information has been shown in a study with a large male cohort (Corden, Critchley, Skuse, \& Dolan, 2006). As mentioned previously, more studies with "typical" adults addressing contextual environmental factors in emotion recognition are needed, especially longitudinal studies.

These findings provide a useful step towards an understanding of early FrFs contribution to affective processing in adulthood and generate a series of important questions to be addressed in future studies, some of the limitations of this study should be noted. Firstly, the siblings' role in affective processing could not control for the impact of age differences. Furthermore, a larger sample size than the one used in Experiment 3 is needed to investigate how maternal and paternal authority styles interact in the modulation of affective processing. Nonetheless, the findings reported here pave the way for studies addressing the development of affective processing in contextualised settings, especially in typical adults (i.e. with no record of severe abuse, stress or other forms of parental neglect during childhood and/or adolescence).

In conclusion, the findings reported here suggest that FrFs are associated with the decoding of microexpressions usually displayed in contexts of danger or distress. The heightened response for the recognition of sadness in adults who perceived their mothers as authoritative could be linked to models of helping and vicarious affect, which in turn have been associated with empathy (Fultz, Schaller, \& Cialdini, 1988). A higher accuracy for microexpressions signalling environmental danger and animosity (anger, contempt, and fear) was observed in adults with few or no siblings, perceived 
permissive or authoritative fathers, and a slower response to anger and contempt in those adults recalling their fathers as more permissive. The effect sizes ranged from modest to moderate, which was expected since the ability to attribute emotions to others is the result of a myriad of processes as adults continuously re-appraise social interactions. The overall findings reported here are in line with an integrative model of social regulation of emotion (Reeck, Ames, \& Ochsner, 2016) and suggest that early FrFs can act as a fine-tuning mechanism in emotional regulation by increasing or decreasing the sensitivity to microexpressions when adults are faced with restricted processing time, especially emotions linked to hostile social environments.

\section{Acknowledgements}

I would like to thank all research assistants who helped with the data collection and Dr Stephanie Eaton for her kindness and useful comments to the first draft of this work. 
References

Ainsworth, M., Blehar, M., Waters, E., \& Wall, S. (1978). Patterns of attachment. Hillsdale, NJ: Erlbaum.

Barber, B. K. (1996). Parental psychological control: Revisiting a neglected construct. Child Development, 67, 3296-3319. doi: 10.2307/1131780

Barrett, L. F. (2006). Are emotions natural kinds? Perspectives on Psychological Science, 1, 28-58

Bartholomew, K., \& Horowitz, L. M. (1991). Attachment styles among young adults: A test of a four-category model. Journal of Personality and Social Psychology, 61, 226-244. doi: $10.1017 / \mathrm{S} 0954579400000110$

Bartholomew, K., \& Shaver, P. R. (1998). Methods of assessing adult attachment. Do they converge? In J. A. Simpson \& W. S. Rholes (Eds.), Attachment theory and close relationships (pp. 25-45). New York: Guilford Press.

Baumrind, D. (1971). Current patterns of parental authority. Developmental Psychology Monographs, 4 (1 pt 2), 1. doi: 10.1037/h0030372

Baumrind, D. (1991). The influence of parenting style on adolescent competence and substance use. Journal of Early Adolescence, 11, 56-95

Bean, R. A., Bush, K. R., McKenry, P. C., \& Wilson, S. M. (2003). The impact of parental support, behavioral control, and psychological control on the academic achievement and self-esteem of African American and European American adolescents. Journal of Adolescent Research, 18, 523-541. doi: 10.1177/0743558403255070

Biehl, M., Matsumoto, D., Ekman, P., Hearn, V., Heider, K., Kudoh, T., \& Ton, V. (1997). Matsumoto and Ekman's Japanese and Caucasian facial expressions of emotion (JACFEE): reliability data and cross-national differences. Joumal of Nonverbal Behavior, 21, 3-21

Biele, C., \& Grabowska, A. (2006). Sex differences in perception of emotion intensity in dynamic and static facial expressions. Experimental Brain Research, 171, 1-6

Bifulco, A., Kwon, J., Jacobs, C., Moran, P. M., Bunn, A., \& Beer, N. (2006). Adult attachment style as mediator between childhood neglect/abuse and adult depression and anxiety. Social Psychiatry and Psychiatric Epidemiology, 41(10), 796-805

Bowlby, J. (1969). Disruption of affectional bonds and its effects on behaviour. Canada's Mental Health Supplement, 59

Box, G. E. P., \& Cox, D. R. (1964). An analysis of transformations. Journal of the Royal Statistical Society. Series B, 26, 211-252

Buri, J. R. (1991). Parental Authority Questionnaire. Journal of Personality and Social Assessment, $57,110-119$

Buri, J. R., Louiselle, P. A., Misukanis, T. M., \& Mueller, R. A. (1988). Effects of parental authoritarianism and authoritativeness on self-esteem. Personality and Social Psychology Bulletin, 14, 271-282

Camras, L. A., Sullivan, J., \& Michel, G. (1993). Do infants express discrete emotions? Adult judgements of facial, vocal, and body actions. Iournal of Nonverbal Behavior, 17, 171-186

Castro, V. L., Halberstadta, A. G., Lozada, F. T., \& Craig, A. B. (2015). Parents' emotion-related beliefs, behaviours, and skills predict children's recognition of emotion. Infant and Child Development, 24, 1-22

Cohen, J. (1990). Things I have learned (so far). American Psychologist, 45, 1304-1312

Cohen, J. (1992). A power primer. Psychological Bulletin, 112, 155-159

Collins, W. A., \& Russell, G. (1991). Mother-child and father-child relationships in middle childhood and adolescence: A developmental analysis. Developmental Review, 11, 99-136

Cooper, M. L., Shaver, P. R., \& Collins, N. L. (1998). Attachment styles, emotion regulation, and adjustment in adolescence. Journal of Personality and Social Psychology, 74(5), 1380-1397 
Corden, B., Critchley, H. D., Skuse, D., \& Dolan, R. J. (2006). Fear recognition ability predicts differences in social cognitive and neural functioning in men. Journal of Cognitive Neuroscience, 18(6), 889-897. doi: 10.1162/jocn.2006.18.6.889

Cui, L., Morris, A. S., Criss, M. M., Houltberg, B. J., \& Silk, J. S. (2014). Parental psychological control and adolescent adjustment: The role of adolescent emotion regulation. Parenting: Science and Practice, 14, 47-67. doi: 10.1080/15295192.2014.880018

de Gelder, B., Meeren, H. K. M., Righart, R., Van den Stock, J., van de Riet, W. A. C., \& Tamietto, M. (2006). Beyond the face: Exploring rapid influences of context on face processing. Progress in Brain Research, 155, 37-48

Delicato, L. S., Finn, J., Morris, J., \& Smith, B. (2014). Increased sensitivity to happy compared with fearful faces in a temporal two-interval forced-choice paradigm. . Perception, 43S, 75-76

Dodich, A., Cerami, C., Canessa, N., Crespi, C., Marcone, A., Arpone, M., . . . Cappa, S. F. (2014). Emotion recognition from facial expressions: a normative study of the Ekman 60-Faces Test in the Italian population. Neurological Sciences, 35, 1015-1021. doi: 10.1007/s10072-0141631-x

Downey, D. B. (2001). Number of siblings and intellectual development: The resource dilution explanation. American Psychologist, 56, 497-504

Downey, D. B., \& Condron, D. J. (2004). Playing well with others in kindergarten: the benefit of siblings at home. Journal of Marriage and Family, 66, 333-350

Dunsmore, J. C., Bradburn, I. S., Costanzo, P. R., \& Fredrickson, B. L. (2009). Mothers' expressive style and emotional responses to children's behavior predict children's prosocial and achievement-related self-ratings. . International Journal of Behavioral Development, 33, 253264

Durand, K., Gallay, M., Seigneuric, A., Robichon, F., \& Jean-Yves, B. (2007). The development of facial emotion recognition : the role of configural information. Journal of Experimental Child Psychology, 97(1), 14-27

Eisenberg, N., Fabes, R. A., Schaller, M., Miller, P., Carlo, G., Poulin, R., . . Shell, R. (1991). Personality and socialization correlates of vicarious emotional responding. Journal of Personality and Social Psychology, 61(3), 459-470

Ekman, P. (1992). Facial expressions of emotion: new findings, new questions. Psychology Science, 3, 34-38

Ekman, P., \& Friesen, W. V. (1978). Facial action coding system: A technique for the measurement of facial movement. Palo Alto, CA: Consulting Psychologists Press.

Ekman, P., Friesen, W. V., O’Sullivan, M., Chan, A., Diacoyanni-Tarlatzis, I., Heider, K., . . . Tomita, M. (1987). Universals and cultural differences in the judgments of facial expressions of emotion. Journal of Personality and Social Psychology, 53, 712-717

Ekman, P., \& Heider, K. G. (1988). The universality of a contempt expression: A replication. Motivation and Emotion, 14(5), 303-308

Ekman, P., \& Oster, H. (1979). Facial expressions of emotion. Annual Review of Psychology, 30, 527-554

Elfenbein, H. A., \& Ambady, N. (2002). On the universality and cultural specificity of emotion recognition: a meta-analysis. Psychological Bulletin, 128, 203-235

Fabes, R. A., Eisenberg, N., Karbon, M., Bernzweig, J., Speer, A. L., \& Carlo, G. (1994). Socialization of children's vicarious emotional responding and prosocial behavior: Relations with mothers' perceptions of children's emotional reactivity. Developmental Psychology, 30(1), 44-55

Faul, F., Erdfelder, E., Lang, A.-G., \& Buchner, A. (2007). G*Power 3: A flexible statistical power analysis program for the social, behavioral, and biomedical sciences. . Behavior Research Methods, 39, 175-191 
Feeney, J. A., \& Noller, P. (1990). Attachment style as a predictor of adult romantic relationships. Journal of Personality and Social Psychology, 58(2), 281-291. doi: 10.1037/00223514.58.2.281

Ford, B. Q., \& Mauss, I. B. (2015). Culture and emotion regulation. Current Opinion in Psychology, 3, 1-5. doi: http://dx.doi.org/10.1016/j.copsyc.2014.12.004

Fraley, R. C., Niedenthal, P. M., Marks, M., Brumbaugh, C., \& Vicary, A. (2006). Adult attachment and the perception of emotional expressions: Probing the hyperactivating strategies underlying anxious attachment. Journal of Personality, 74(4), 1163-1190

Griffin, D. W., \& Bartholomew, K. (1994). Models of the self and other: Fundamental dimensions underlying measure of adult attachment. Journal of Personality and Social Psychology, 67, 430-445

Haggard, E. A., \& Isaacs, K. S. (1966). Micro-momentary facial expressions as indicators of ego mechanisms in psychotherapy. In L. A. Gottschalk \& A. H. Auerbach (Eds.), Methods of Research in Psychotherapy (pp. 154-165). New York: Appleton-Century-Crofts.

Halberstadt, A. G. (1986). Family socialisation of emotional expression and nonverbal communication styles and skills. Journal of Personality and Social Psychology, 51, 827-836

Halberstadt, A. G., Dennis, P. A., \& Hess, U. (2011). The influence of family expressiveness, individuals' own emotionality, and self-expressiveness on perceptions of others' facial expressions. Journal of Nonverbal Behavior, 35, 35-50

Hazan, C., \& Shaver, P. (1987). Romantic love conceptualized as an attachment process. Journal of Personality and Social Psychology, 42, 511-524

Hess, U., Blairy, S., \& Kleck, R. E. (1997). The intensity of emotional facial expressions and decoding accuracy. Journal of Nonverbal Behavior, 21, 241-257

Hiroto, D. S. (1974). Locus of control and learned helplessness. Journal of Experimental Psychology, 102, 187-193

Hiroto, D. S., \& Seligman, M. E. P. (1975). Generality of learned helplessness in man. Journal of Personality and Social Psychology, 31, 311-327

Izard, C. E. (1994). Innate and universal facial expressions: evidence from developmental and crosscultural research. Psychological Bulletin, 115(2), 288-299

Jack, R. E., Caldara, R., \& Schyns, P. G. (2012). Internal representations reveal cultural diversity in expectations of facial expressions of emotion. Journal of Experimental Psychology: General, $141(1), 19-25$

Karim, A. K. M. R., Sharafat, T., \& Mahmud, A. Y. (2013). Cognitive emotion regulation in children as related to their parenting style, family type and gender. Journal of the Asiatic Society of Bangladesh, Science 39(2), 211-220

Kemeny, M. E., Foltz, C., Cavanagh, J. F., Cullen, M., Giese-Davis, J., Jennings, P., . . Ekman, P. (2012). Contemplative / emotion training reduces negative emotional behavior and promotes prosocial responses. Emotion, 12(2), $338-350$

Kestenbaum, R., \& Nelson, C. A. (1992). Neural and behavioural correlates of emotion recognition in children and adults. Journal of Experimental Child Psychology, 54, 1-18

Kiel, E. J., \& Kalomiris, A. E. (2015). Current themes in understanding children's emotion regulation as developing from withing the parent-child relationship. Current Opinion in Psychology, 3, $11-16$

Klein, H. A., O'bryant, K., \& Hopkins, H. R. (1996). Recalled Parental Authority Style and SelfPerception in College Men and Women. The Journal of Genetic Psychology: Research and Theory on Human Development, 157(1), 5-17. doi: 10.1080/00221325.1996.9914842

Kunz, J. H., \& Grych, J. H. (2013). Parental psychological control and autonomy granting: Distinctions and associations with child and family functioning. Parenting: Science and Practice, 13 77-94. doi: 10.1080/15295192.2012.709147 
Levine, T. R., \& Hullett, C. R. (2002 ). Eta squared, partial eta squared, and misreporting of effect size in communication research. Human Communication Research, 28(4), 612-625

Magai, C., Hunziker, J., Mesias, W., \& Culver, L. C. (2000). Adult attachment styles and emotional biases. International Journal of Behavioral Development, 24, 301-309. doi: $10.1080 / 01650250050118286$

Marsman, M., \& Wagenmakers, E.-J. (2016). Bayesian benefits with JASP. European Journal of Developmental Psychology, 1-11. doi: 10.1080/17405629.2016.1259614

Matsumoto, D., \& Ekman, P. (1988). Japanese and Canadian Facial Expressions (JACFEE) and Neutral Faces (JACneut). . San Francisco San Francisco State University.

Matsumoto, D., LeRoux, J., Wilson-Cohn, C., Raroque, J., Kooken, K., Ekman, P., . . Goh, A. (2000). A new test to measure emotion recognition ability: Matsumoto and Ekman Japanese and Caucasian Brief Affect Recognition Test ( JACBART). Journal of Nonverbal Behaviour, 24, 179-209

McElwain, N. L., Halberstadt, A. G., \& Volling, B. L. (2007). Mother- and Father-reported reactions to children's negative emotions: relations to young children's emotional understanding and friendship quality. Child Development, 78(5), 1407-1425. doi: 10.1111/j.14678624.2007.01074.x

Morris, A. S., Silk, J. S., Steinberg, L., Myers, S. S., \& Robinson, L. R. (2007). The role of the family context in the development of emotion regulation. Social Development, 16(2), 361388. doi: http://doi.org/10.1111/j.1467-9507.2007.00389.x

Niedenthal, P. M., Brauer, M., Robin, L., \& Innes-Ker, Å. (2002). Adult attachment and the perception of facial expression of emotion. Journal of Personality and Social Psychology, 83(3)

Nitsch, A., Faurie, C., \& Lummaa, V. (2013). Are elder siblings helpers or competitors? Antagonistic fitness effects of sibling interactions in humans. Proceedings of the Royal Society B, 2080(1750), 20122313. doi: 10.1098/rspb.2012.2313 1471-2954

Nook, E. C., Lindquist, K. A., \& Zaki, J. (2015). A new look at emotion perception: Concepts speed and shape facial emotion recognition. Emotion, 15(5), 569-578

Palermo, R., \& Coltheart, M. (2004). Photographs of facial expression: Accuracy, response times, and ratings of intensity. Bheaviour Research Methods, Instructions, \& Computers, 36(4), 634-638

Ravitz, P., Maunder, R., Hunter, J., Stankiya, B., \& Lancee, W. (2010). Adult attachment measures: A 25-year review. Journal of Psychosomatic Research, 69, 419-432

Reeck, C., Ames, D. R., \& Ochsner, K. N. (2016). The social regulation of emotion: An integrative, cross-disciplinary model. Trends in Cognitive Sciences, 20(1), 47-63. doi: http://dx.doi.org/10.1016/j.tics.2015.09.003

Roesch, E. B., Sander, D., Mumenthaler, C., Kerzel, D., \& Scherer, K. R. (2010). Psychophysics of emotion: The QUEST for emotional attention. Journal of Vision, 10(3), 1-9

Safer, M. A. (1981). Sex and hemisphere differences in access to codes for processing emotional expressions and faces. Journal of Experimental Psychology: General, 110(1), 86-100

Schlegel, K., Grandjean, D., \& Scherer, K. R. (2014). Introducing the Geneva Emotion Recognition Test: An example of Rasch-based test development. . Psychological Assessment, 26, 666-672

Shaffer, A., Burt, B. K., Obradovic, J., Herbers, J. E., \& Masten, A. S. (2009). Intergenerational continuity in parenting quality: The mediating role of social competence. Developmental Psychology, 45(5), 1227-1240. doi: 10.1037/a0015361

Shen, X., Wu, Q., \& Fu, X. (2012). Effects of the duration of expressions on the recognition of microexpressions. Journal of Zhejiang University-SCIENCE B (Biomedicine \& Biotechnology), 13(3), 221-230

Shortt, J. W., Stoolmiller, M., Smith-Shine, J. N., Mark Eddy, J., \& Sheeber, L. (2010). Maternal emotion coaching, adolescent anger regulation, and siblings' externalizing symptoms. Journal 
of Child Psychology \& Psychiatry, 51(7), 799-808. doi: doi: 10.1111/j.14697610.2009.02207.x

Silk, J. S., Steinberg, L., \& Morris, A. S. (2003). Adolescents' emotion regulation in daily life: Links to depressive symptoms and problem behavior. . Child Development, 74, 1869-1880

Simpson, J. A., \& Rholes, W. S. (1998). Attachment theory and close relationships. New York, NY: The Guilford Press.

Wagenmakers, E.-J., Morey, R. D., \& Lee, M. D. (2016). Bayesian benefits for the pragmatic researcher. Current Directions in Psychological Science, 25, 169-176

Wills, T. A., \& Yaeger, A. M. (2003). Family factors and adolescent substance use: models and mechanisms. Current Directions in Psychological Science, 12(6), 222-226

Yan, W.-J., Wu, Q., Liang, J., Chen, Y.-H., \& Fu, X. (2013). How fast are the leaked facial expressions: the duration of micro-expressions. Journal of Nonverbal Behavior, 47(4), 217230

Young, J. C., \& Widom, C. S. (2014). Long-term effects of child abuse and neglect on emotion processing in adulthood. Child Abuse Negl. , 38(8), 1369-1381. doi: 10.1016/j.chiabu.2014.03.008

Young, S. G., \& Hugenberg, K. (2010). Mere social categorization modulates identification of facial expressions of emotion. Journal of Personality and Social Psychology, 99, 964-977 


\section{TABLES}

Table 1. Mean accuracy and reaction time for the six microexpressions in Experiment $1(N=$ 137), Experiment $2(N=79)$, and Experiment $3(N=65)$. Values refer to the mean $( \pm$ S.E.) [95\% confidence intervals].

\begin{tabular}{lcr}
\hline & Accuracy (\%) & Reaction Time (ms) \\
\hline \multicolumn{3}{c}{ Experiment 1 } \\
\hline Anger & $61(3)[56,66]$ & $1575(106)[1366,1784]$ \\
Contempt & $88(2)[84,92]$ & $1089(76)[939,1239]$ \\
Disgust & $55(3)[50,60]$ & $1577(116)[1349,1806]$ \\
Fear & $74(3)[68,79]$ & $1345(96)[1154,1535]$ \\
Happiness & $96(1)[94,97]$ & $814(45)[726,902]$ \\
Sadness & $68(3)[62,73]$ & $1430(101)[1230,1630]$ \\
\hline & Experiment 2 & \\
\hline Anger & $68(3)[63,73]$ & $1739(73)[1594,1886]$ \\
Contempt & $92(1)[87,94]$ & $1610(85)[1441,1779]$ \\
Disgust & $66(3)[59,72]$ & $1682(81)[1521,1843]$ \\
Fear & $90(2)[87,93]$ & $1572(76)[1422,1723]$ \\
Happiness & $96(1)[94,98]$ & $1222(54)[1114,1330]$ \\
Sadness & $76(3)[70,86]$ & $1759(68)[1624,1894]$ \\
\hline & Experiment 3 & \\
\hline Anger & $63(4)[56,70]$ & $2239(162)[1916,2562]$ \\
Contempt & $88(3)[83,93]$ & $2543(442)[1661,3425]$ \\
Disgust & $55(3)[48,61]$ & $2890(281)[2329,3451]$ \\
Fear & $86(3)[80,91]$ & $2037(201)[1646,2438]$ \\
Happiness & $97(1)[94,99]$ & $1386(116)[1154,1617]$ \\
Sadness & $80(3)[74,86]$ & $2048(294)[1460,2636]$ \\
\hline
\end{tabular}

URL: http:/mc.manuscriptcentral.com/pqje 
Table 2. Correlations between the accuracy for microexpressions and early family-related environmental factors: number of siblings $(N=137)$ and perceived authority styles of mother and fathers $(N=65)$.

\begin{tabular}{lccccc}
\hline & Anger & \multicolumn{2}{c}{ Contempt } & Disgust & \multicolumn{2}{l}{ Fear } & \multicolumn{2}{c}{ Sadness } \\
& -.135 & -.017 & -.061 & $-.181^{*}$ & -.037 \\
No. siblings & -.154 & $-.319^{* *}$ & -.145 & $-.378^{* *}$ & -.073 \\
Authoritarian father & -.084 & $.260^{*}$ & .008 & .073 & .066 \\
Authoritative father & -.118 & $.316^{* *}$ & .064 & .200 & -.133 \\
Permissive father & .099 & -.118 & .058 & -.198 & -.189 \\
Authoritarian mother & -.064 & .010 & -.014 & .138 & $.316^{* *}$ \\
Authoritative mother & -.213 & .146 & -.229 & -.044 & .128 \\
Permissive mother & & & & & \\
\hline
\end{tabular}

$* p<.05 ; * * p \leq .01 ; * * * p \leq .0001$ (2-tailed). 
Table 3. Individual regression coefficients for different predictors of the accuracy (top) and $\mathrm{RT}$ (bottom) to $100 \mathrm{~ms}$ microexpressions (in bold). The adjusted $R$-squared is indicated as $\Delta$ Accuracy or $\Delta \mathrm{RT}$. For more details, see text.

\begin{tabular}{|c|c|c|c|c|c|}
\hline$\Delta$ Accuracy & $R^{2}$ & B & S.E. B & $\beta$ & Constant \\
\hline $\begin{array}{l}\text { Contempt } \\
\text { Authoritarian father } \\
\text { Permissive father } \\
\text { Authoritative father }\end{array}$ & $\begin{array}{l}8.7 \% \\
8.6 \% \\
6.8 \% \\
\end{array}$ & $\begin{array}{l}-.011 \\
.014 \\
.010 \\
\end{array}$ & $\begin{array}{l}.004 \\
.005 \\
.005 \\
\end{array}$ & $\begin{array}{l}-.319 * * \\
.316 \\
.260 \\
\end{array}$ & $\begin{array}{l}1.159 \\
.453 \\
.499 \\
\end{array}$ \\
\hline $\begin{array}{l}\text { Fear } \\
\text { Number of siblings } \\
\text { Authoritarian father }\end{array}$ & $\begin{array}{r}3.3 \% \\
13.0 \% \\
\end{array}$ & $\begin{array}{l}-.047 \\
-.013 \\
\end{array}$ & $\begin{array}{l}.022 \\
.004 \\
\end{array}$ & $\begin{array}{l}-.181 * \\
-.378 * * \\
\end{array}$ & $\begin{array}{r}.811 \\
1.164 \\
\end{array}$ \\
\hline $\begin{array}{l}\text { Sadness } \\
\text { Authoritative mother }\end{array}$ & $8.6 \%$ & .012 & .005 & $.316^{* *}$ & .271 \\
\hline$\Delta R T$ & $R^{2}$ & B & S.E. B & $\beta$ & Constant \\
\hline $\begin{array}{l}\text { Anger } \\
\text { Permissive father }\end{array}$ & $8.3 \%$ & .000 & .000 & $.312 *$ & .016 \\
\hline $\begin{array}{l}\text { Contempt } \\
\text { Number of siblings } \\
\text { Permissive father }\end{array}$ & $\begin{array}{l}2.6 \% \\
8.2 \%\end{array}$ & $\begin{array}{r}-.001 \\
.000\end{array}$ & $\begin{array}{l}.001 \\
.000 \\
\end{array}$ & $\begin{array}{l}-.181 * \\
.311^{* *}\end{array}$ & $\begin{array}{l}.037 \\
.015 \\
\end{array}$ \\
\hline $\begin{array}{l}\text { Fear } \\
\text { Fearful attachment }\end{array}$ & $5.3 \%$ & -81.789 & 35.343 & $-.255^{*}$ & 1834.731 \\
\hline $\begin{array}{l}\text { Sadness } \\
\text { Number of siblings }\end{array}$ & $5.8 \%$ & -.002 & .001 & $.255 * *$ & .035 \\
\hline
\end{tabular}


Table 4. Descriptive statistics for the questionnaires used in this study: RQ at the top part of the table $(N=79)$ and PAS at the bottom $(N=65)$. Fathers $=\lambda$, Mothers $=q$.

\begin{tabular}{lcccc}
\hline & Secure & Preoccupied & Fearful & Avoidant \\
\hline Secure & 1 & -.137 & $-.365^{* * *}$ & $-.248^{*}$ \\
Preoccup & & 1 & $.336^{* *}$ & -.192 \\
ied & & & & \\
Fearful & & & 1 & .035 \\
Avoidant & & & & 1
\end{tabular}

\begin{tabular}{|c|c|c|c|c|c|c|}
\hline & $\begin{array}{c}\text { Authoritarian } \\
\overline{0}\end{array}$ & Authoritative & $\begin{array}{c}\text { Permissive } \\
\hat{0}\end{array}$ & $\begin{array}{c}\text { Authoritarian } \\
o\end{array}$ & $\begin{array}{c}\text { Authoritative } \\
q\end{array}$ & $\begin{array}{c}\text { Permissive } \\
\propto\end{array}$ \\
\hline Authoritarian ${ }^{\wedge}$ & 1 & $-.284^{*}$ & $-.437 * *$ & .137 & .123 & .135 \\
\hline Authoritative $\widehat{ }{ }^{\lambda}$ & & 1 & $.254 *$ & .123 & .162 & -.010 \\
\hline Permissive $\lesssim$ & & & 1 & .137 & $-.303 *$ & .239 \\
\hline Authoritarian $q$ & & & & 1 & $-.552 * *$ & $-.574 * *$ \\
\hline Authoritative $q$ & & & & & 1 & .225 \\
\hline Permissive $q$ & & & & & & 1 \\
\hline
\end{tabular}


FIGURE AND LEGEND
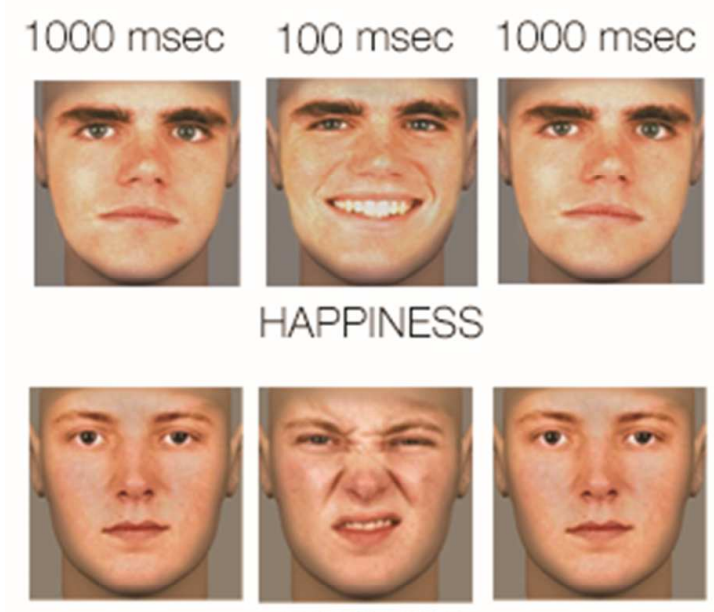

DISGUST

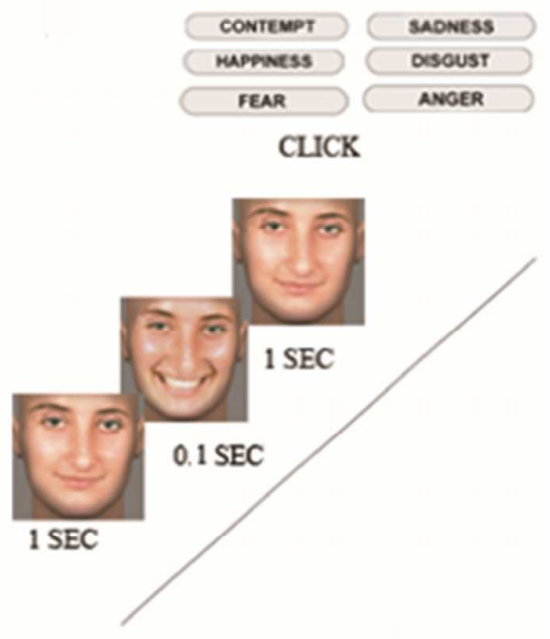

Figure 1. Schematic illustration of the experimental setup. (Left) Examples of microexpressions from the Japanese and Caucasian Facial Expressions of Emotion and neutral faces (JACFEE/JACneut) database overlaid on generic avatars. (Right) The response was given by mouseclicking the box with the emotion label corresponding to the microexpression presented (middle image). The sequences of microexpressions were randomly interleaved and counterbalanced in all experiments. 

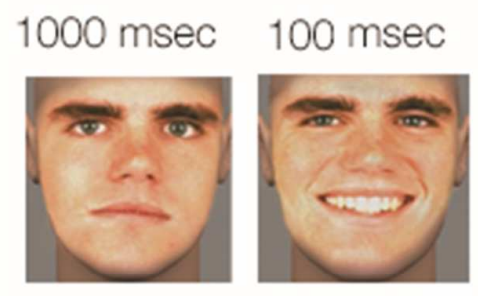

HAPPINESS
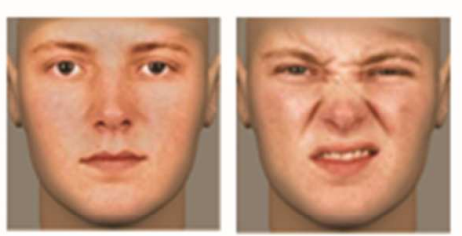

DISGUST
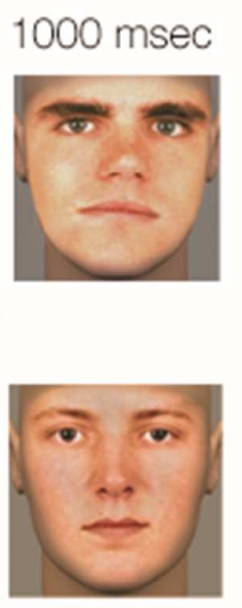

19

20

21

22

23

24

25

26

27

28

29

30

31

32

33

34

35

36

37

38

39

40

41

42

43

44

45

46

47

48

49

50

51

52

53

54

55

56

57

58

59

60 
Table 1. Mean accuracy and reaction time for the six microexpressions in Experiment $1(N=137)$, Experiment $2(N=79)$, and Experiment $3(N=65)$. Values refer to the mean $( \pm$ S.E. $)[95 \%$ confidence intervals].

\begin{tabular}{|c|c|c|}
\hline & Accuracy (\%) & Reaction Time (ms) \\
\hline \multicolumn{3}{|c|}{ Experiment 1} \\
\hline Anger & $61(3)[56,66]$ & $1575(106)[1366,1784]$ \\
\hline Contempt & $88(2)[84,92]$ & $1089(76)[939,1239]$ \\
\hline Disgust & $55(3)[50,60]$ & $1577(116)[1349,1806]$ \\
\hline Fear & $74(3)[68,79]$ & 1345 (96) $[1154,1535]$ \\
\hline Happiness & $96(1)[94,97]$ & $814(45)[726,902]$ \\
\hline Sadness & $68(3)[62,73]$ & $1430(101)[1230,1630]$ \\
\hline \multicolumn{3}{|c|}{ Experiment 2} \\
\hline Anger & $68(3)[63,73]$ & $1739(73)[1594,1886]$ \\
\hline Contempt & $92(1)[87,94]$ & $1610(85)[1441,1779]$ \\
\hline Disgust & $66(3)[59,72]$ & $1682(81)[1521,1843]$ \\
\hline Fear & $90(2)[87,93]$ & $1572(76)[1422,1723]$ \\
\hline Happiness & $96(1)[94,98]$ & $1222(54)[1114,1330]$ \\
\hline Sadness & $76(3)[70,86]$ & $1759(68)[1624,1894]$ \\
\hline \multicolumn{3}{|c|}{ Experiment 3} \\
\hline Anger & $63(4)[56,70]$ & $2239(162)[1916,2562]$ \\
\hline Contempt & $88(3)[83,93]$ & $2543(442)[1661,3425]$ \\
\hline Disgust & $55(3)[48,61]$ & $2890(281)[2329,3451]$ \\
\hline Fear & $86(3)[80,91]$ & $2037(201)[1646,2438]$ \\
\hline Happiness & 97 (1) $[94,99]$ & $1386(116)[1154,1617]$ \\
\hline Sadness & $80(3)[74,86]$ & $2048(294)[1460,2636]$ \\
\hline
\end{tabular}


Table 2. Correlations between the accuracy for microexpressions and early familyrelated environmental factors: number of siblings $(N=137)$ and perceived authority styles of mother and fathers $(N=65)$.

\begin{tabular}{lccrrrr}
\hline & Anger & Contempt & Disgust & Fear & \multicolumn{2}{c}{ Sadness } \\
\hline No. siblings & -.135 & -.017 & -.061 & $-.181^{*}$ & -.037 \\
Authoritarian father & -.154 & $-.319^{* *}$ & -.145 & $-.378^{* *}$ & -.073 \\
Authoritative father & -.084 & $.260^{*}$ & .008 & .073 & .066 \\
Permissive father & -.118 & $.316^{* *}$ & .064 & .200 & -.133 \\
Authoritarian mother & .099 & -.118 & .058 & -.198 & -.189 \\
Authoritative mother & -.064 & .010 & -.014 & .138 & $.316^{* *}$ \\
Permissive mother & -.213 & .146 & -.229 & -.044 & .128 \\
\hline$* p<.05 ; * p \leq .01 ; * * * p \leq .0001$ (2-tailed). & & &
\end{tabular}


Table 3. Individual regression coefficients for different predictors of the accuracy (top) and RT (bottom) to $100 \mathrm{~ms}$ microexpressions (in bold). The adjusted $R$-squared is indicated as $\Delta$ Accuracy or $\Delta \mathrm{RT}$. For more details, see text.

\begin{tabular}{|c|c|c|c|c|c|}
\hline$\Delta$ Accuracy & $R^{2}$ & B & S.E. B & $\boldsymbol{\beta}$ & Constant \\
\hline \multicolumn{6}{|l|}{ Contempt } \\
\hline Authoritarian father & $8.7 \%$ & -.011 & .004 & $-.319 * *$ & 1.159 \\
\hline Permissive father & $8.6 \%$ & .014 & .005 & .316 & .453 \\
\hline Authoritative father & $6.8 \%$ & .010 & .005 & .260 & .499 \\
\hline \multicolumn{6}{|l|}{ Fear } \\
\hline Number of siblings & $3.3 \%$ & -.047 & .022 & $-.181 *$ & .811 \\
\hline Authoritarian father & $13.0 \%$ & -.013 & .004 & $-.378 * *$ & 1.164 \\
\hline \multicolumn{6}{|l|}{ Sadness } \\
\hline Authoritative mother & $8.6 \%$ & .012 & .005 & $.316^{* *}$ & .271 \\
\hline$\Delta R T$ & $\boldsymbol{R}^{2}$ & B & S.E. B & $\boldsymbol{\beta}$ & Constant \\
\hline \multicolumn{6}{|l|}{ Anger } \\
\hline Permissive father & $8.3 \%$ & .000 & .000 & $.312 *$ & .016 \\
\hline \multicolumn{6}{|l|}{ Contempt } \\
\hline Number of siblings & $2.6 \%$ & -.001 & .001 & $-.181 *$ & .037 \\
\hline Permissive father & $8.2 \%$ & .000 & .000 & $.311 * *$ & .015 \\
\hline \multicolumn{6}{|l|}{ Fear } \\
\hline Fearful attachment & $5.3 \%$ & -81.789 & 35.343 & $-.255^{*}$ & 1834.731 \\
\hline \multicolumn{6}{|l|}{ Sadness } \\
\hline Number of siblings & $5.8 \%$ & -.002 & .001 & $.255^{* *}$ & .035 \\
\hline
\end{tabular}


Table 4. Descriptive statistics for the questionnaires used in this study: RQ at the top part of the table $(N=79)$ and PAS at the bottom $(N=65)$. Fathers $=\hat{\sigma}$, Mothers $=q$.

\begin{tabular}{|c|c|c|c|c|c|c|}
\hline & Secure & Preoccupied & Fearful & Avoidant & & \\
\hline Secure & 1 & -.137 & $-.365^{* *}$ & $-.248^{*}$ & & \\
\hline Preoccup & & 1 & $.336^{* *}$ & -.192 & & \\
\hline Fearful & & & 1 & .035 & & \\
\hline \multirow[t]{3}{*}{ Avoidant } & & & & 1 & & \\
\hline & Authoritarian & Authoritative & Permissive & Authoritarian & Authoritative & Permissive \\
\hline & $\hat{0}$ & $\hat{0}$ & $\hat{0}$ & q & q & q \\
\hline 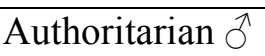 & 1 & $-.284^{*}$ & $-.437 * *$ & .137 & .123 & .135 \\
\hline Authoritative ${ }^{\lambda}$ & & 1 & $.254^{*}$ & .123 & .162 & -.010 \\
\hline Permissive $\sigma^{\lambda}$ & & & 1 & .137 & $-.303 *$ & .239 \\
\hline Authoritarian $q$ & & & & 1 & $-.552 * *$ & $-.574 * *$ \\
\hline Authoritative $q$ & & & & & 1 & .225 \\
\hline Permissive $\bigcirc$ & & & & & & 1 \\
\hline
\end{tabular}

